\title{
Biocompatibility and Immunocompatibility Assessment of Poly(2-Oxazolines)
}

\author{
Juraj Kronek, Ema Paulovičová, Lucia Paulovičová, \\ Zuzana Kroneková and Jozef Lustoň
}

Additional information is available at the end of the chapter

http://dx.doi.org/10.5772/51501

\section{Introduction}

Synthetic polymers are considered to be the promising materials for biomedical applications. Various polymer formulations have been employed to achieve the desired chemical, physical and biological properties. Recently, there has been much interest in the development of environmentally responsive polymers for use as biomaterials [1]. Such behavior is significant for the controlled release of drugs upon the application of a stimulus, such as $\mathrm{pH}$, temperature, light or ionic strength. These mentioned properties are necessary for the utilization of polymeric materials for biomedical applications, such as drug and gene delivery, biomembrane technology and biocatalysis [2,3]. Polymer materials can be used in medicine as a part of implant, dialysis membranes, bone scaffolds or components of artificial organs. It means that polymers covers very broad range of biomedical applications. A critical point of the usage of synthetic polymers in living bodies is their utilization, accompanied with the interactions of the foreign material, with the living matter (cells, tissues etc.). The implantation of polymeric materials to a body is usually associated with the inflammation and biofouling. The inflammation is the first defense mechanism of the immune system followed by unspecific cell and protein adhesion and the formation of fibrotic tissue which leads to implant's dysfunctions. The fundamental role in the implantation of these materials is to increase the tolerance of body to implanted material and to avoid the foreign body reaction $[4,5]$.

Assessments of polymeric material biocompatibility and immunotoxicity are key issues to consider material to be suitable for biomedical applications. Biocompatibility assessment of a polymeric material includes adequate testing for undesired responses. To evaluate biocompatibility, examinations of acute and system toxicity, tissue cultures, cell growth inhibition, mutagenicity, carcinogenicity, teratogenicity and allergenic potential should be 
conducted [6]. In vitro cytotoxicity can be tested by a number of methods that are mostly based on the colorimetric assay of dyes that are sensitive to viable or dead cells. Such assays include 3-(4,5-dimethylthiazol-2-yl)-2,5-diphenyltetrazolium bromide (MTT), 2,3-bis-(2methoxy-4-nitro-5-sulfophenyl)-2H-tetrazolium-5-carboxanilide (XTT), water soluble tetrazolium salts (WST), trypan blue or sulforhodamine B as dyes.

The immunocompatibility of polymers is obviously compulsory for their potential medical application. Several aspects of targeted immune responses have to be taken into account. The immune system is an integrated system composed of two major sub-systems, the innate, non-specific immune system and the adaptive, specific immune system. The innate immune system represents a primary defense mechanism against invading microorganisms and foreign substances and the adaptive immune system operates as a second part of defense. Systemic host immune responses involve complex and multisided interactions between numerous mechanisms of innate and adaptive immunities and their cellular and humoral components. Apart from systemic immunity, common mucosal immune system is effective in all mucosal surfaces i.e. mucosa-associated lymphoid tissue (MALT), including aggregates and diffuse population of immune cells within mucosae; gut-associated lymphoid tissue (GALT), including isolated lymphoid follicles, Peyer's patches, the appendix, and cells in the lamina propria; bronchus-associated lymphoid tissue (BALT), including defined aggregates and diffuse populations of lymphoid cells around the airways [7].

Several specifically programmed cells are involved in innate and adaptive immunity. These include neutrophiles and macrophages, which are involved in phagocytosis, basophils and mast cells, which are involved in inflammation and B and T lymphocytes which account for antibody mediated immunity and cell mediated immunity, respectively. Most of immune system's immunocompetent effector cells are derived from specific precursors in the bone marrow. In addition to red blood cells and platelets, pluripotent stem cells give rise to the lymphocytes, the monocytes and macrophages, and to the group of cells with collective term "the granulocytes", covering neutrophils, basophils and eosinophils.

Dendritic cells (DCs) comprise a subset of cells with different characteristics, derived from bone marrow precursor cells. Dendritic cells are professional antigen presenting cells that play a central role in the running and regulation of immune responses, as well as control the innate (NK cells, NKT cells, $\gamma \delta$ T cells) and adaptive (T and B cells) arm of immunity DCs have a crucial role in initiating T-cell mediated immunity. DCs'can control a substantial part of the adaptive immune response by internalizing and processing antigen through MHCclass I and class II pathways and, finally, presenting antigenic peptides to $\mathrm{CD} 4^{+}$and CD8 ${ }^{+} \mathrm{T}$ lymphocytes [8-10].

The specific adaptive immune system requires some time period to act in a response to an invader (microorganism or foreign substance), whereas the non-specific innate immune system comprises fundamental defenses mostly constitutively present and mobilized immediately upon the invasion and recognition of foreign invader. Macrophages and the progeny of granulocyte differentiation, tissue-based mast cells and NK cells are decisive cellular components of the innate immune response. Monocyte-derived macrophages represent the first line of host defence after the epithelial barrier against invader that reaches 
mucosal surfaces. Hence they are one of the most crucial cells acting in innate immune responses to exogenous challenge. They are equipped with restricted number of pattern recognition receptors (PRRs) to recognize foreign invader via their pathogen-associated molecular patterns (PAMPs). Pattern recognition receptors (PRRs) are membrane-bound or secreted microbial sensory receptors that include Toll-like receptors (TLRs), Nod-like receptors (NLRs), and C-type lectin receptor (CLRs). The main functions of PRRs' include opsonization, activation of complement and coagulation cascades, phagocytosis, induction of inflammatory cytokines, and induction of apoptosis. Innate immune responses are triggered upon PAMPs recognition by the Toll-like receptors (TLR), type I transmembrane signalling cell surface molecules. Activation of TLRs induces, via the transcriptional activator nuclear factor $\mathrm{kB}(\mathrm{NF}-\mathrm{kB})$, the triggering of a wide variety of inflammatory and immune-response genes and expression of a variety of molecules in macrophages including pro-inflammatory cytokines e.g. tumor necrosis factor - $\alpha$ (TNF- $\alpha)$, interleukin-1 (IL-1), interleukin 6 (IL-6), interferons (IFN- $\gamma$, IFN $\beta$ ), granulocyte-colony stimulating factor (GCSF), granulocyte-macrophage colony-stimulating factor (GM-CSF), transforming growth factor (TGF- $\beta$ ), macrophage inflammatory protein 1 (MIP-1) [11-13].

Host immune responses towards biomaterials and biocompatibility and immunocompatibility of polymeric materials are essentially important for their biomedical application. Recently, strategies of triggering appropriate immune responses by functional biomaterials and approaches of biomaterials that mimic the physiological extracellular matrix and modify cellular immune responses have been highlighted [14]. The targeting of dendritic cells with biopolymers [15] and targeting antigen to immune cells via PAMPmodified biomaterials [16] have received considerable attention and represents the novel strategy to control the subsequent immune responsiveness. Immunological inflammation comprising the temporal variation in the acute inflammatory response, chronic inflammatory response, granulation tissue development, and foreign-body reaction represents one of the most important reactions to biomaterials observed in a host $[17,18]$. Immunogenicity of synthetic biopolymers, their immunomodulative character and induction of cell and antibody immunities are crucial aspects of in vivo applications. The involvement of the immune system in incompatibility reactions towards biomaterials is not desirable in special cases, thus, various possibilities to shield the biomaterial and cell surfaces from recognition by the innate immune system are studied [19].

The aim of this chapter is to summarize and evaluate the available methods for the biocompatibility and immunocompatibility assesment of 2-oxazoline-based polymers. 2Oxazoline-based polymers serve a significant role in the field of polymers suitable for biological and medical use. Examples of their applications in field of biology and medicine were also given.

\section{Poly(2-oxazolines) as materials for biomedical applications}

From a variety of synthetic polymers suitable for different biomedical applications, polymers based on 2-oxazoline chemistry represent very versatile and promising materials. 
Poly(2-oxazolines) can be prepared by the living cationic polymerization of 2-oxazolines containing aliphatic or aromatic substituent [20] (Fig. 1). This means that polymers with defined structure, size and narrow dispersity can be prepared. Living character of polymerization of 2-oxazolines can be employed for the preparation of polymers with complex architecture, such as star-shaped polymers [21,22] or polymer combs and brushes [23], and also for the synthesis of block copolymers.<smiles>[R]C1=NCCO1</smiles>
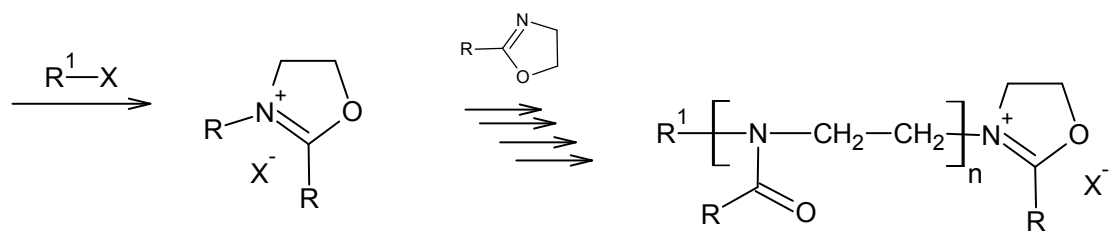

Figure 1. Scheme of living cationic polymerization of 2-substituted 2-oxazolines.

Polymers containing functional groups represent an important part of polymer therapeutics, especially in the drug delivery systems. Polymers containing functional groups in the side chain can be prepared directly from the 2-oxazoline monomer containing the required group, or by polymer analogous reaction of polymer precursors. Preparation of polymers containing amino, carboxyl, mercapto, and aldehyde groups in the side chain was reported [24-26]. In all cases, monomers containing a protected functional group were used for the polymer synthesis. The protecting group was removed after the polymerization process was completed. Copolymers containing a free amino group were prepared directly by the cationic copolymerization of 2-ethyl-2-oxazoline and 2-(4-aminophenyl)-2-oxazoline [27].

Poly(2-alkyl-2-oxazolines) with shorter alkyl chain are water soluble and exhibit thermosensitive behaviour (Fig. 2). Poly(2-ethyl-2-oxazoline) (PETOX) represents a thermoresponsive polymer with the lower critical solution temperature (LCST) equal to 69 ${ }^{\circ} \mathrm{C}$ [28]. Poly(2-isopropyl-2-oxazoline) (PIPOX) also exhibits thermosensitive behavior, and its LCST is near $37^{\circ} \mathrm{C}$, which is necessary for its utilization in drug and gene delivery [29]. Poly(2-propyl-2-oxazoline) (PPOX) has LCST equal to $25^{\circ} \mathrm{C}$ [30]. These results show that the length of alkyl chain has a great impact on solution properties of poly(2-alkyl- 2-oxazolines) and phase transition can be adjusted also by copolymerization of monomers with different alkyl chain.<smiles>CCC(=O)N1CCC1(C)C</smiles>

PETOX<smiles>CC(C)C(=O)N1CCC1(C)CC(C)(C)C</smiles>

PIPOX<smiles>CCCC(=O)N1CCC1(C)C</smiles>

PPOX

Figure 2. Structure of thermosensitive poly(2-oxazolines). 
Due to their versatility and ability to form functional materials and nanostructures, 2oxazoline based polymers have a promising use in biomedical applications. One of the principal application areas for polymers in biological and medicinal contexts is drug and gene delivery. The concept of drug delivery is based on either encapsulation of a drug in polymer and its delivery through diffusion or covalent attachment onto functional polymer matrix through labile bond [31]. The majority of polymers that have been investigated for use in drug and gene delivery applications have focused on linear polymers such as poly(ethylene oxide) (PEO), poly(N-2-hydroxypropyl methacrylamide) (HPMA) and others. One possibility is based on the preparation of liposome-polyoxazoline conjugates [32,33]. Prepared poly(2-methyl-2-oxazoline) (PMEOX) and poly(2-ethyl-2-oxazoline) (PETOX) containing the carboxylic group positioned at either the initiation or termination ends of the polymer chains. Distearoylphosphatidylethanolamine was covalently attached to the polymers through the carboxyl end groups, resulting in conjugates which incorporate readily into liposomes. Both polymers exhibit long plasma lifetimes and low hepatosplenic uptake.

Another possibility is the preparation of amphiphilic block copolymers consisted of either blocks of hydrophilic and hydrophobic 2-oxazoline monomers or blocks of hydrophilic poly(2-oxazoline) and another hydrophobic polymer. In such manner, amphiphilic block copolymers containing poly(2-ethyl-2-oxazoline) as hydrophilic block and polycaprolactone as hydrophobic block have been prepared (Fig. 3b). Such block copolymers are able to form micelles in aqueous solution and can be exploited for delivery of paclitaxel (Fig. 3a) [34]. Similarly, sustained release of the antibody bevacizumab (Avastin) from a biocompatible material based on triblock copolymer of poly(2-ethyl-2-oxazoline)-block- poly(epsiloncaprolactone)-block- poly(2-ethyl-2-oxazoline) has been reported by Wang et al. [35]. Bevacizumac has been used clinically to treat intraocular neovascular diseases based on its antivascular endothelial growth factor (VEGF) character.

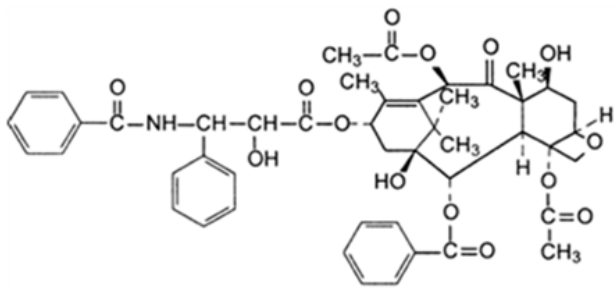

(a)

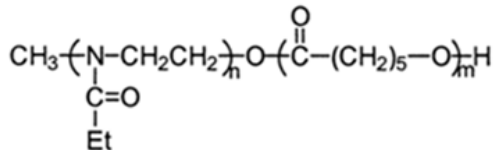

(b)

Figure 3. Structure of paclitaxel (a) and poly(2-ethyl-2-oxazoline)-block- poly(epsilon-caprolactone) (b).

Amphiphilic graft copolymers with a thermosensitive poly(N-isopropylacrylamide) (PNiPAAM) backbone and $\mathrm{pH}$-sensitive hydrophilic poly(2-carboxyethyl-2-oxazoline) graft chains were prepared and used for the formation of stable micelle-like aggregates with reversible thermosensitive and $\mathrm{pH}$ dependent swelling behaviour [36]. The temperatureswitchable hydrophilicity or swelling of the core as well as the pHdependent stretching of 
the side chains in these core-shell nanogels offers a great potential for applications such as drug delivery systems or nanoreactors/carriers in biotechnology. Nanoparticles based on block copolymers of 2-ethyl-2-oxazoline and 2-phenyl-2-oxazolines were studied as promising tools for targeted delivery of drugs in the treatment of neuropsychiatric disorders [37].

Polymers based on 2-oxazoline chemistry were also used in gene delivery. Polyethylene imine (PEI) is one of widely used vectors for nucleic acid delivery. It was found that linear PEI is more effective than branched PEI prepared by conventional polymerization of aziridine. Therefore, DNA complex with fully deacylated PEI can be used in gene therapy for lung diseases [38]. On the other hand, partially hydrolyzed poly(2-ethyl-2-oxazoline) showed lower cytotoxicity comparing to PEI and hasstill high transfection efficiency in the gene expression [39]. Linear PEI can be prepared by basic or acidic hydrolysis of poly(2ethyl-2-oxazoline). Recently, microwave synthesizer induced hydrolysis of poly(2-ethyl-2oxazoline) was described as powerful method for the preparation of "pharmagrade" PEI [40]. A block copolymer of a hyperbranched poly(ethylene glycol)-like core and linear polyethylenimine (HBP) was prepared by cationic polymerization of 2-ethyl-2-oxazoline initiated by hyperbranched initiator bearing p-chloromethylbenzoyl initiating groups and subsequent hydrolysis [41]. Linear PEI-bearing hyperbranched polycations (HBP) is able to form a complex with DNA with an average diameter of $50 \mathrm{~nm}$ that is stable for several weeks and showed resistance to DNAse I-mediated degradation. The 'inverted' block copolymers showed several orders higher transfection efficiency than block copolymers of PEG-b-LPEI in vitro. Comb-like copolymers suitable for DNA transfection consisted of linear poly(ethyleneimine)-graft-poly(2-ethyl-2-oxazoline) (LPEI-comb-PETOX) and (ethyleneimine)-graft-poly(ethyleneimine) (LPEI-comb-LPEI) [42]. Successful gene delivery systems with high transfection efficiency was prepared also by condensation of therapeutic DNA with different copolymers of poly(L-lysine)-graft-poly(2-methyl-2-oxazoline) of variable grafting densities [43]. Amphiphilic poly[(propylene glycol)-block-(2-methyl-2oxazoine)] block copolymers were studied for gene transfer in skeletal muscle [44].

Poly(2-oxazolines) have found utilization also in vaccine technology. Recently, a novel glycoconjugates consisting of detoxified lipopolysaccharide of Vibrio cholerae O135, linear poly(2-oxazoline) copolymer containing free amino groups as a carrier, and an immunogenic protein, BSA, has been prepared. Multiple attachments of small effector antigen molecules to a suitable matrix is considered a novel technique for creating efficient glycoconjugate vaccines $[45,46]$.

Antimicrobial polymers are becoming increasingly important materials in the face of spreading microbial infections and increasing microbial resistance to antibiotics. Waschinski et al. recently reported the synthesis of poly(2-methyl-2-oxazolines) and poly(2-ethyl-2oxazolines) with quarternary ammonium terminating groups [47]. The polymers were prepared via standard cationic ring-opening polymerisation and terminated using a series of $\mathrm{N}$-alkyl-N,N-dimethyl amines as well as pyridine (Fig. 4). The study of antimicrobial properties toward Staphylococcus aurea showed that only poly(2-methyl-2-oxazoline)-based 
polymers containing alkyl ammonia functions with alkyl chains of twelve carbon atoms or longer exhibit antimicrobial activity.

Polymers based on 2-oxazoline chemistry were used in biotechnology for different applications. Biofouling release properties are important for the development of coatings exhibiting marine biofouling resistance. It was found that copolymers prepared from perfluoroalkyl acrylates and poly(2-isopropenyl-2-oxazoline) exhibited unprecedented resistance to marine biofouling [48]. Another example is the development of an optical biosensor using an electrically controlled-release system for measurement of peroxide concentration. The response is based on the hydrogen bond of carboxylic group of currentsystem and 2-oxazoline group of a polymer complex [49]. Activating enzymes in organic solvents is of great interest in current biocatalysis. Amphiphilic and liposome-like polymers have exploitation also in membrane technology. Amphiphilic polymer tether consisted of linear hydrophilic poly(2-methyl-2-oxazoline) chains with defined length with surfacecoupling silane groups on one chain-end and hydrophobic n-alkyl chains on second end [50]. These polymers represent linear polymer spacers between supported lipid membranes and solid substrates. Lipid-tehtered poly(2-methyl-2-oxazoline) lipopolymer chains can be used as Langmuir monolayers at the air-water interface [51]. Recently, novel alpha,omegafunctionalized amphiphilic lipopolymers based on a proximal lipid moiety and hydrophilic poly(2-oxazoline) were used in asymmetric functionalized model lipid membranes for transmembrane transport and cell adhesion/recognition [52]. Amphiphilic co-networks composed of more hydrophilic poly(2-hydroxyethyl acrylate) and more hydrophobic, telechelic poly(2-ethyl-2-oxazoline) segments were prepared as free-standing membranes for entrapment of an enzyme molecule [53]. Amphiphilic miktoarm star copolymers containing cyclodextrin core can be used as nanocarriers in drug delivery but also in biocatalysis. Amphiphilic copolymers were consisted of poly(2-ethyl-2-oxazoline) and polylactide arms covalently linked to cyclodextrine core [54].

All reported applications of poly(2-oxazolines) confirm a great potential of 2-oxazoline based polymers as biomaterials. Detailed study of their biocompatibility and immunocompatibility is essential and necessary to understand their interactions with the living systems (biomolecules, cells, tissues etc.).

\section{Methods for the assessment of cytotoxicity of poly(2-oxazolines)}

Generally, biocompatibility is the ability of a material to perform with an appropriate host response in a specific application [55]. It was already mentioned that biocompatibility assessment includes different assays of acute and system toxicity, tissue cultures, cell growth inhibition, mutagenicity, carcinogenicity, teratogenicity and allergenic potential. In vitro cytotoxicity can be measured by different laboratory assays, such as the 3-(4,5dimethylthiazol-2-yl)-2,5-diphenyltetrazolium bromide (MTT) assay, 2,3-bis-(2-methoxy-4nitro-5-sulfophenyl)-2H-tetrazolium-5-carboxanilide (XTT) assay, Trypan blue (TB) assay, Sulforhodamine B (SRB) assay, WST assay and clonogenic assay. 
The MTT assay is a laboratory test and a standard colorimetric assay for measuring cellular growth. It can also be used to determine cytotoxicity of potential medicinal agents and other toxic materials [56]. Yellow MTT is reduced to purple formazan in the mitochondria of living cells (Fig. 4). A solubilization solution (usually dimethyl sulfoxide, an acidified ethanol solution or a solution of the detergent sodium dodecyl sulfate in dilute hydrochloric acid) is added to dissolve the insoluble purple formazan product into a colored solution. The absorbance of this colored solution can be quantified by measuring at a certain wavelength (usually between 500 and $600 \mathrm{~nm}$ ) by a UV-Vis spectrophotometer. The absorption maximum is dependent on the solvent employed. This reduction takes place only when mitochondrial reductase enzymes are active, and therefore conversion can be directly related to the number of viable (living) cells. When the amount of purple formazan produced by cells treated with an agent is compared with the amount of formazan produced by untreated control cells, the effectiveness of the agent in causing death of cells can be deduced (Fig. 4.).
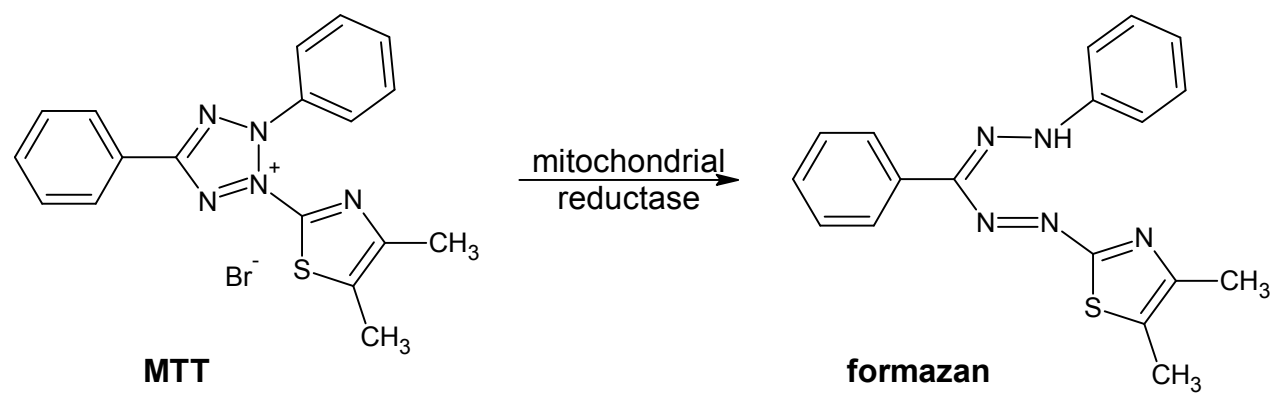

Figure 4. Scheme of reduction of the MTT to fozmazan.

The principle of the WST assay is the same as in the case of MTT assay. In contrast to the MTT assay, no extraction step was necessary due to the water solubility of the reduced form of 2-(4-iodophenyl)-3-(4-nitrophenyl)-5-(2,4-disulfophenyl)-2H-tetrazolium (WST-1) so that absorbance could be determined directly at $450 \mathrm{~nm}$ after conversion [57]. The same principle is used in the XTT assay which employs 2,3-bis-[2-methoxy-4-nitro-5-sulphophenyl]-2Htetrazolium-5-carboxanilide (XTT) as reagent.

Trypan blue is a vital stain used to selectively color dead tissues or cells blue (Fig. 5). Live cells or tissues with intact cell membranes are impermeable for Trypan bluesince cells are very selective in the compounds that pass through the membrane. Trypan blue is not absorbed. In dead cells, the dye traverses the membrane and dead cells are stained blue under a microscope.

Sulforhodamine B or Kiton Red is a fluorescent dye with uses spanning from L.I.F.(Laser Induced Fluorescense) to the quantification of cellular proteins of cultured cells. The red, solid, water soluble dye is primarily used as a polar tracer. The dye absorbs $565 \mathrm{~nm}$ light and emits $586 \mathrm{~nm}$ light. It does not exhibit $\mathrm{pH}$ dependent absorption or fluorescence over the range of 3 to 10 [58]. 


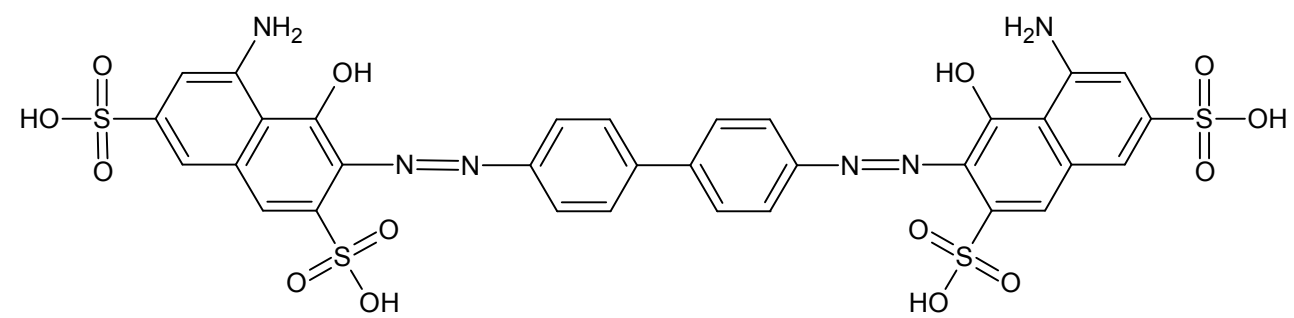

trypan blue

Figure 5. Structure of Trypan blue

A clonogenic assay is a microbiology technique for studying the effectiveness of specific agents on survival and proliferation of cells. It is frequently used in cancer research laboratories to determine the effect of drugs or radiation on proliferating tumor cells [59]. Although this technique can provide accurate results, the assay is time-consuming to set up and analyse and can only provide data on tumor cells that can grow in culture. The word "clonogenic" refers to the fact that these cells are clones of one another.

The experiment involves three major steps:

1. The treatment is applied to a sample of cells.

2. The cells are "plated" in a tissue culture vessel and allowed to grow.

3. The colonies produced are fixed, stained, and counted.

At the conclusion of the experiment, the percentage of cells that survived the treatment is measured. A graphical representation of survival versus drug concentration or dose of ionizing radiation is called a cell survival curve.

Although a number of assays can be employed for the estimation of in vitro cytotoxicity of different materials, the MTT assay was used almost exclusively for the assessment of in vitro cytotoxicity of poly(2-oxazoline)s and 2-oxazoline related polymers. The cytotoxicity of poly(2-ethyl-2-oxazoline) (PETOX) as a function of hydrolysis to linear poly(ethylene imine) (PEI) was studied by conducting an MTT assay [60]. It was found that cell viability decreased with an increasing degree of hydrolysis, and above $50 \%$ hydrolysis the cell viability decreased to $20 \%$. Another example of this polymer as a suitable material for medical use is employing polymeric micelles of poly(2-ethyl-2-oxazoline)-block-poly( $\varepsilon$ caprolactone) copolymer (PETOX-PCLs) as a carrier for paclitaxel as mentioned above. It was showed that the viability of KB human epidermoid carcinoma cells in the presence of PETOX-PCL copolymers were in the range 80 to $100 \%$ depending on the concentration of the copolymer solution and also on the ratio of both building blocks [34]. Similarly, polymeric micelles prepared from poly(2-ethyl-2-oxazoline)-b-poly(l-lactide) diblock copolymers (PETOX-PLLA) have been considered biomaterials for drug delivery. PETOXPLLA polymeric micelles had low cytotoxicity in human normal fibroblast HFW cells for 72 $\mathrm{h}$ by using MTT assay. It was found that cell viability was higher than $80 \%$ for the concentration range below $1 \mathrm{mg} / \mathrm{ml}$ [61]. Structure-uptake relationships of a series of 
amphiphilic poly(2-oxazolines) block copolymers that have different architectures, molar mass and chain termini were reported [62]. The relative cytotoxicity of poly(2-oxazolines) was tested on MCF7-ADR cells derived from human breast carcinoma cell line, MCF7 (ATCC HT-B22). All tests confirmed that these polymers are typically not cytotoxic even at high concentrations. The rate of endocytosis can be fine-tuned over a broad range by changing the polymer structure. The cellular uptake of the polymers increased with their hydrophobic character.

Low cytotoxicity of aliphatic poly(2-alkyl-2-oxazoline)s was confirmed also in in vitro studies with Rat-2 fibroblasts using the MTT test [63] (Figs. 6 and 7). The dependence of cell viability on molar mass confirmed the expected trend; the viability increased with the higher molar mass of poly(2-ethyl-2-oxazoline), up to $15000 \mathrm{~g} / \mathrm{mol}$. The effect of incubation time and concentration was also studied. It was shown that cell viability is in the range of untreated control even after 48 hours and the polymer concentration up to 5 $\mathrm{mg} / \mathrm{ml}$ (Fig. 7b).

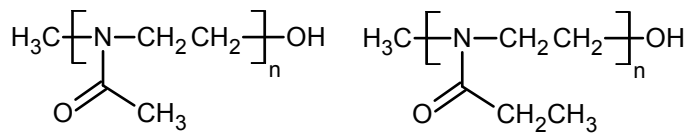<smiles>CCC(=O)N(CCCC(C)O)CCC(=O)C1=CC=C2CC=C3CC=CC4=CC=C1C2C43</smiles>

PMEOX PETOX PETOX-py

Figure 6. Structures of measured poly(2-alkyl-2-oxazolines)

a)

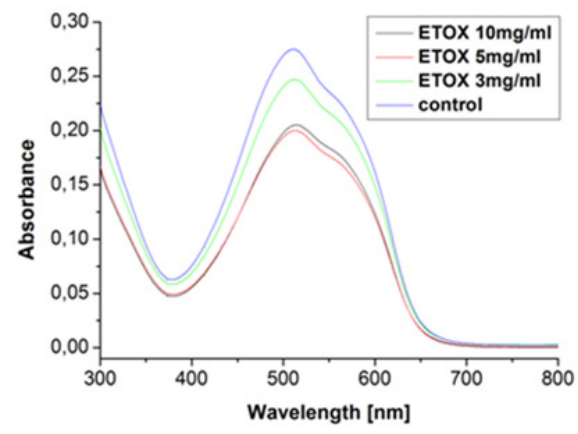

b)

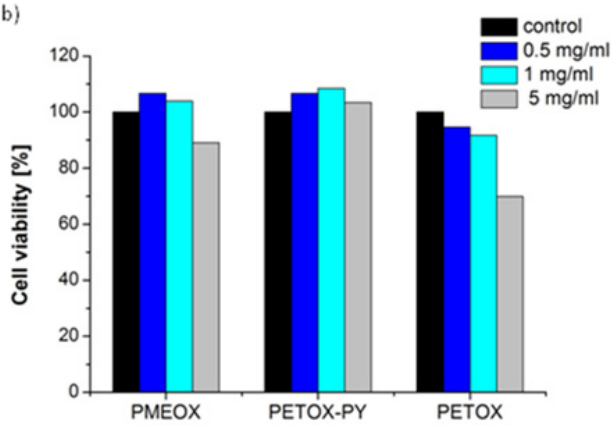

Figure 7. a) UV spectra of the reduced formazan dissolved in DMSO after incubation of rat fibroblasts with PETOX, b) relative cell viability of selected 2-oxazolines. PMEOX - poly(2-methyl-2-oxazoline), PETOX - poly(2-ethyl-2-oxazoline), PETOX-py - pyrene labelled poly(2-ethyl-2-oxazoline).

The results obtained for the polymers with aliphatic side chains were compared with the analogues that possessed an aromatic moiety. It is known from the literature that the presence of benzene ring in many cases increases their toxicity as was showed for 
different aromatic drugs [64,65]. In spite of these results, our measurements indicated that the presence of a benzene ring in poly[2-ethyl-2-oxazoline-co-2-(4-aminophenyl)-2oxazoline] with 10 mol. \% aromatic moiety (AEOX10) (synthesis see Fig. 8) has no affect on the growth and proliferation of cells and that the values of cytotoxicity measured in the MTT test were on the same level as in the case of PETOX and PMEOX [27,63]. All results confirmed low cytotoxicity of the polymers prepared by cationic polymerization of 2-alkyl- and 2-aryl-2-oxazolines, which supports their utilization in biomedical applications.<smiles>CCC1=NCCO1</smiles><smiles>CCC(=O)N(CCCC(C)(C)O)CC(C)(C)N(CCCN1CC(C)(O)C1)C(=O)c1ccc(N)cc1</smiles>

AEOX10

Figure 8. Synthesis of poly[2-ethyl-2-oxazoline-co-2-(4-aminophenyl)-2-oxazoline] (9:1).

\section{Methods for the assessment of immunocompatibility of poly(2-oxazolines)}

Selected techniques as flow cytometric simultaneous evaluation of phagocytosis accompanied by oxidative burst, immunocytometric determination of $T_{\mathrm{H}} 1 / \mathrm{T}_{\mathrm{H}} 2 / \mathrm{T}_{\mathrm{H}} 17$ cytokines using bead application and enzyme-linked spot evaluation of cytokine producing cells comprise novel approaches to characterise and consider immunomodulation of basic functions of immunocompetent cells targeted by biopolymers.

\subsection{Assessment of phagocyte functions by immunocytometry}

Macrophages are tissue-based cells belonging to the reticuloendothelial system, capable of phagocytosis and production of an array of immunomodulatory mediators. Foreign substance or invader triggered macrophage activation result in a release of proinflammatory interleukins, growth factors and chemokines and also in up regulation of induction of inducible oxide synthase and other potent reactive oxidants inflicting cell damage. Phagocytosis represents a complex process comprising several subsequent steps i.e. chemotaxis, attachment/adherence onto a phagocytotic membrane, internalization and fusion of the cell membrane, intra- and extracellular digestion of targets, and oxidative burst (Fig. 9). The rate of endocytosis can be fine-tuned over a broad range by changing the polymer structure. The cellular uptake increases with the hydrophobic character of the polymers and is observed even at nanomolar concentrations [62]. 


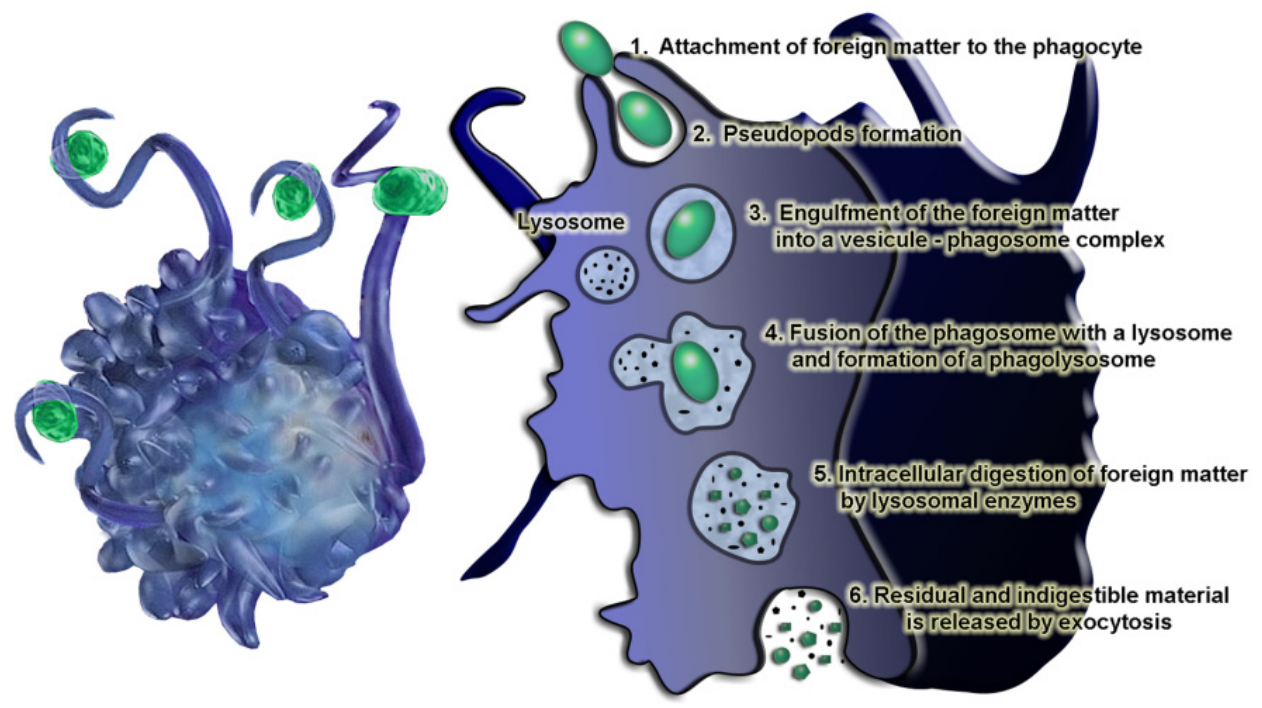

Figure 9. The sequential mechanism of phagocytosis.

Phagocytosing cells undergo a burst of oxygen consumption that is caused by an NADPH oxidase complex that assembles at the phagosomal membrane. Neutrophils and the other phagocytes create $\mathrm{O}_{2}{ }^{-}$(superoxide) by the one-electron reduction of oxygen at the expense of NADPH. A variety of soluble and particular stimuli induce extracellular superoxide production. Most of the oxygen consumed can be accounted for as hydrogen peroxide, which is formed from dismutation of superoxide radical. From these agents a large number of highly reactive microbicidal oxidants are formed, including $\mathrm{HOCl}$ (hypochlorous acid), which is produced by the myeloperoxidase-catalyzed oxidation of $\mathrm{Cl}^{-}$by $\mathrm{H}_{2} \mathrm{O}_{2}$; $\mathrm{OH}^{*}$ (hydroxyl radical), produced by the reduction of $\mathrm{H}_{2} \mathrm{O}_{2}$ by $\mathrm{Fe}^{2+}$ or $\mathrm{Cu}^{+}$; $\mathrm{ONOO}{ }^{*}$ (peroxynitrite), formed by the reaction between $\mathrm{O}_{2}{ }^{-}$and $\mathrm{NO}^{\circ}$, and many others [66]. Reactive oxygen species (ROS) comprises not only free radicals, such as superoxide radical, hydroperoxyl radical, hydroxyl radical, peroxyl radical etc., but also non-radicals, namely hydrogen peroxide, singlet oxygen, and hypochlorous acid. These reactive oxidants are manufactured not only as microbicidal agents, but they also impose cell damage.

Hydroethidine (dihydroethidium; HE) is frequently used as fluorescence probe for the evaluation of cell oxidative burst by detection of ROS (Fig. 10). HE has the ability to cross-cellular membranes becoming therefore efficient in cell oxidative burst studies. When inside the cell the $\mathrm{HE}$ is oxidized by $\mathrm{O}_{2}{ }^{-}$, it originates ethidium $\left(\mathrm{E}^{+}\right)$, which becomes locked in the cell by virtue of its cationic nature. The ethidium intercalates into DNA and is red fluorescent when excited with either visible or UV light. HE can also be oxidized by different reactive species, being the relative reactivity ranked by ONOO$>\mathrm{HO}^{\bullet}>\mathrm{O}_{2}{ }^{-}>\mathrm{H}_{2} \mathrm{O}_{2}$. Thus, $\mathrm{HE}$ provides an index of reactive oxygen and nitrogen species production [67]. 


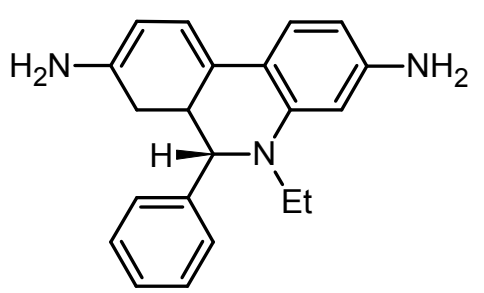

HE

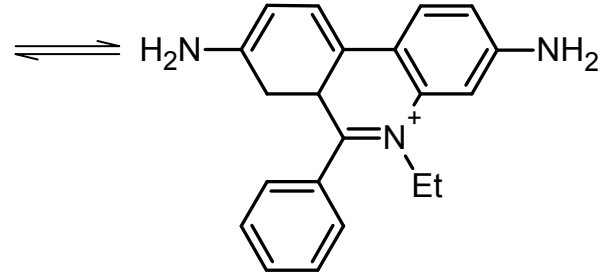

$\mathrm{E}^{+}$

$$
\begin{aligned}
& \lambda_{\mathrm{exc}}=520 \mathrm{~nm} \\
& \lambda_{\mathrm{em}}=610 \mathrm{~nm}
\end{aligned}
$$

Figure 10. Chemical structure of hydroethidine (HE) and ethidium $\left(\mathrm{E}^{+}\right)$.

To follow up the production of ROS throughout the oxidative burst of phagocyte, the fluorescence methodology, associated with the use of suitable fluorescence probes, is an excellent research approach applicable both for fluorescence microscopy and flow cytometry (Fig. 11).

Generally, flow cytometry measures optical and fluorescence characteristics of single cells or any other particles flowing in a single file in a stream of fluid. Light scattering at different angles can distinguish differences in size and internal complexity. Intensity of light scattered in the forward direction i.e. forward angle light scatter (FSC) roughly equates to the particle's size and can be used to distinguish between cellular debris and living cells. Light measured approximately at a $90^{\circ}$ angle to the excitation line is called side scatter. The side scatter channel (SSC) provides information about the granular content within a particle. Fluorescence measurements at different wavelengths $\left(\lambda_{\mathrm{em}}\right)$ can provide qualitative and quantitative data about fluorochrome-labelled cell surface receptors or intracellular molecules such as DNA and cytokines $[68,69]$.

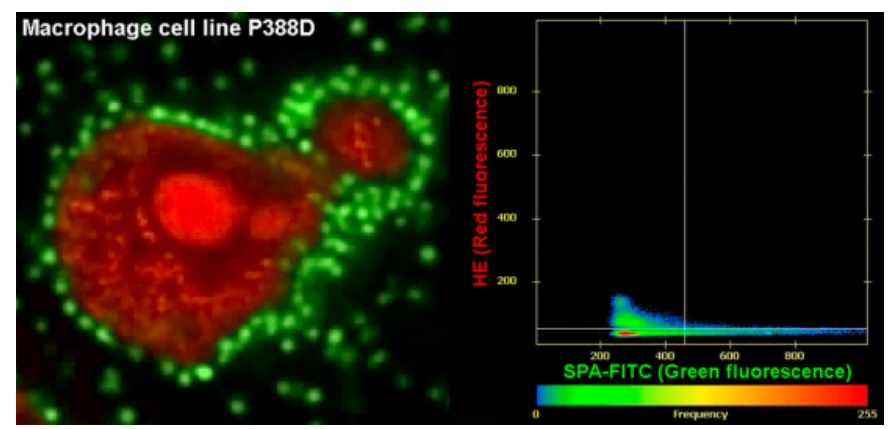

Figure 11. Simultaneous phagocytosis and oxidative burst in mouse macrophage line P388D, by S. aureus BioParticles ${ }^{\circledR}$ FITC labeled (Molecular Probes) in conjunction with dihydroethidium. Visualisation: Confocal Laser Scanning Microscopy LSM 710, Cell Observer (Zeiss). 
Assessment of phagocyte functions i.e phagocytosis and oxidative burst using S. aureusFITC and fluorescent probe HE by flow cytometry is an approach based on the complex imunocytometric analysis of multiple characteristic of individual cells i.e neutrophils, monocyte-derived macrophages (Fig. 12). Analyses were performed with a BeckmanCoulter FC 500 flow cytometer with 488-nm excitation and filters for the detection of green fluorescence $(525 \mathrm{~nm})$ of $S$. aureus BioParticles ${ }^{\circledR}$ FITC labelled and red fluorescence of ethidium (610 nm). Two parameters, MFI (mean fluorescence intensity) and percentage of fluorescence-positive cells were determined separately from approx. 5000 macrophages with a flow rate of 200-300 events/s by gating the cell population according to the forward scatter (FS)/side scatter (SS) histogram. To exclude cell debris and non-ingested S. aureus BioParticles from FS/SS histogram, discriminator was set into the FS channel.
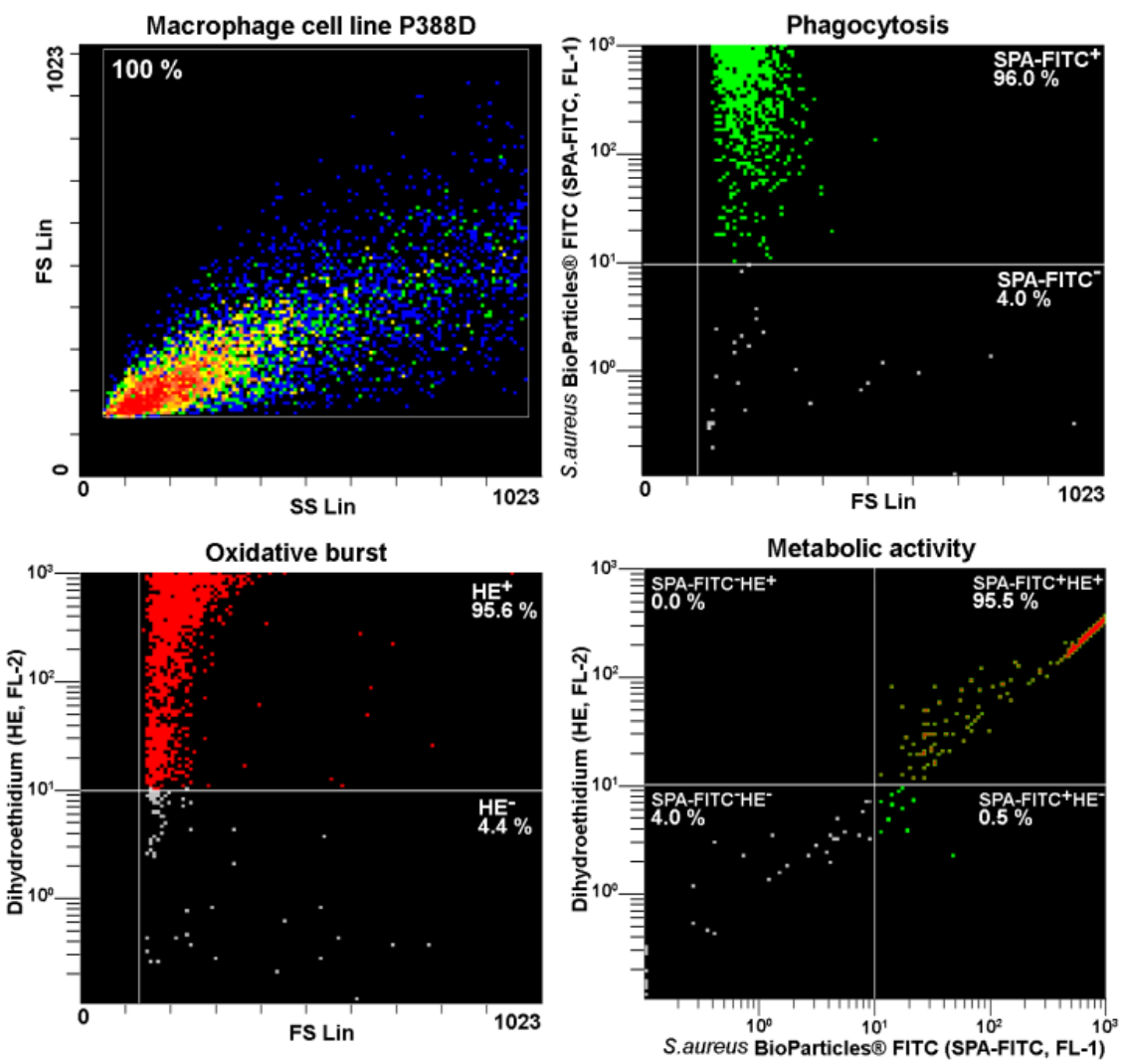

Figure 12. Simultaneous flow cytometric evaluation (Beckman Coulter FC 500) of phagocytosis and oxidative burst in mouse macrophage line P388D, by S.aureus BioParticles ${ }^{\circledR}$ FITC labeled (Molecular Probes), (SPA-FITC) in the conjunction with dihydroethidium (HE). Mean \% of phagocytic cells represents the percentage of granulocytes ingesting at least one SPA-FITC particle; mean \% of oxidative burst represents the percentage of granulocytes tagged by ethidium; mean metabolic activity $\%$ represents the percentage of granulocytes ingested at least one SPA-FITC and were tagged by ethidium. 


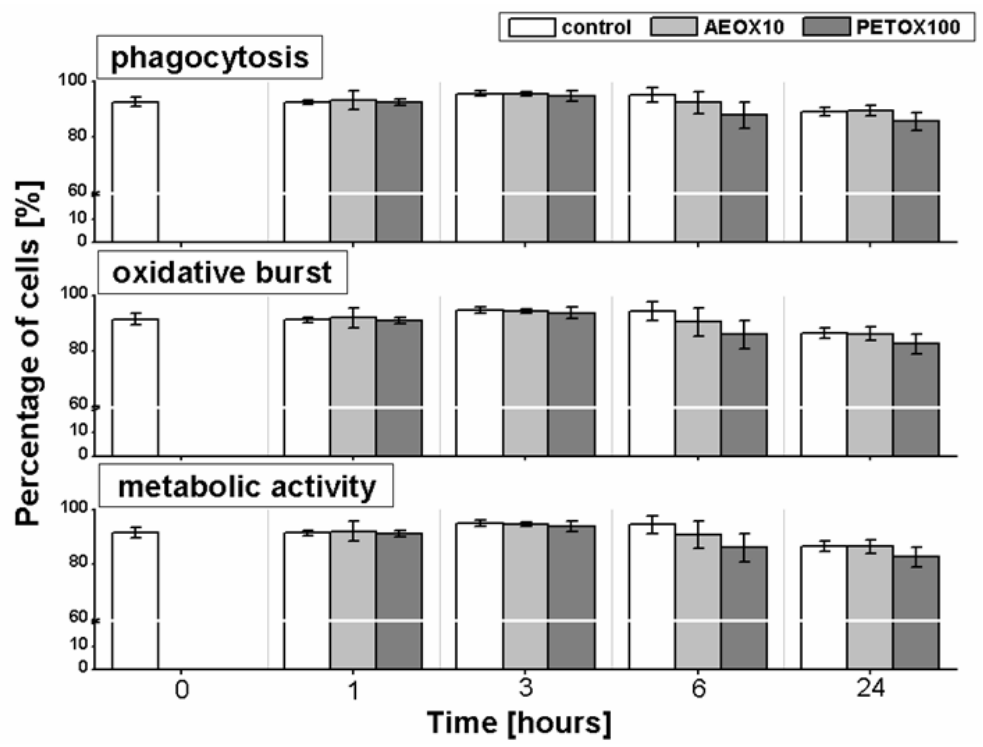

Figure 13. The influence of AEOX10 and PETOX100 (5 mg/ml) on phagocytic effectiveness, oxidative burst and mtabolic activity (phagocytosis and oxidative burst) of macrophages.

In our experiments we analyzed the time and concentration dependent influence of poly(2oxazoline)s: AEOX10 and PETOX100 (PETOX with theoretical degree of polymerization equal to 100) on phagocytosis and oxidative burst of macrophages as representative professional phagocytic cells belonging to innate immune system compartments [63]. The treatment was performed for 1, 3, 6 and 24 hours with selected concentrations $0.5 \mathrm{mg} / \mathrm{ml}$ and $5 \mathrm{mg} / \mathrm{ml}$, respectively. In all experiments the metabolic activity, including phagocytosis and oxidative burs, treated macrophage cell line P388D remained comparable with untreated control cells without any significant immunosuppressive effect of poly(2-oxazoline)s (Fig. 13).

\subsection{Assessment of triggered cytokine release and $\mathrm{T}_{\mathrm{H}}$ polarisation using ELISpot and FlowCytomix ${ }^{\mathrm{TM}}$ assays}

Cytokines are proteins secreted by different cells of the immune system and serve as molecular messengers between cells. Cytokines interact with cells of the immune system in order to regulate the host response to pathological disorders; apart from this they also mediate physiological cellular processes. Different types of cytokines as colony stimulating factors, growth and differentiation factors, immunoregulatory and proinflammatory cytokines are involved in direct cell stimulation, differentiation, development and polarisation of immune response (Fig. 14). CD4 ${ }^{+} \mathrm{T}$ lymphocytes are crucial mediators of the cellular immune response. The early response of naive $\mathrm{CD} 4^{+} \mathrm{T}$ cells to antigenic stimulation (via pattern-recognition receptors) is characterized by induced proliferation. Further differentiation give arise of cells with a significant potential for cytokine expression. Depending upon the balance of local cytokines, co-stimulatory molecules, antigen levels, 
and genetic factors, $\mathrm{T}_{\mathrm{H}} 1, \mathrm{~T}_{\mathrm{H}} 2, \mathrm{~T}_{\mathrm{H}} 17$ effector and/or memory cells and Tregs' are generated by immune responses. Functionally-polarized $\mathrm{CD}^{+} \mathrm{T}$ cell subsets have been identified based on their exclusive patterns of various cytokine secretions. As a signature cytokine, $\mathrm{T}_{\mathrm{H}} 1$ cells selectively produce large amounts of interferon-gamma (IFN- $\gamma$ ). TH2 cells selectively produce IL-4, next characteristic $\mathrm{T}_{\mathrm{H}} 2$ cytokines are IL-5 and IL-13. The population of $\mathrm{T}_{\mathrm{H}} 17$ cells expresses high levels of IL-17A, followed by IL-17AF , IL-17F, IL-21 and IL-22. Unique cytokine expression for Tregs' represents TGF- $\beta$ and IL-10. The $\mathrm{T}_{\mathrm{H}} 1 / \mathrm{T}_{\mathrm{H}} 2 / \mathrm{T}_{\mathrm{H}} 17 / \mathrm{Treg}$ paradigm provides a useful model system for investigating the cellular and molecular mechanisms that mediate protective as well as harmful immune responses.

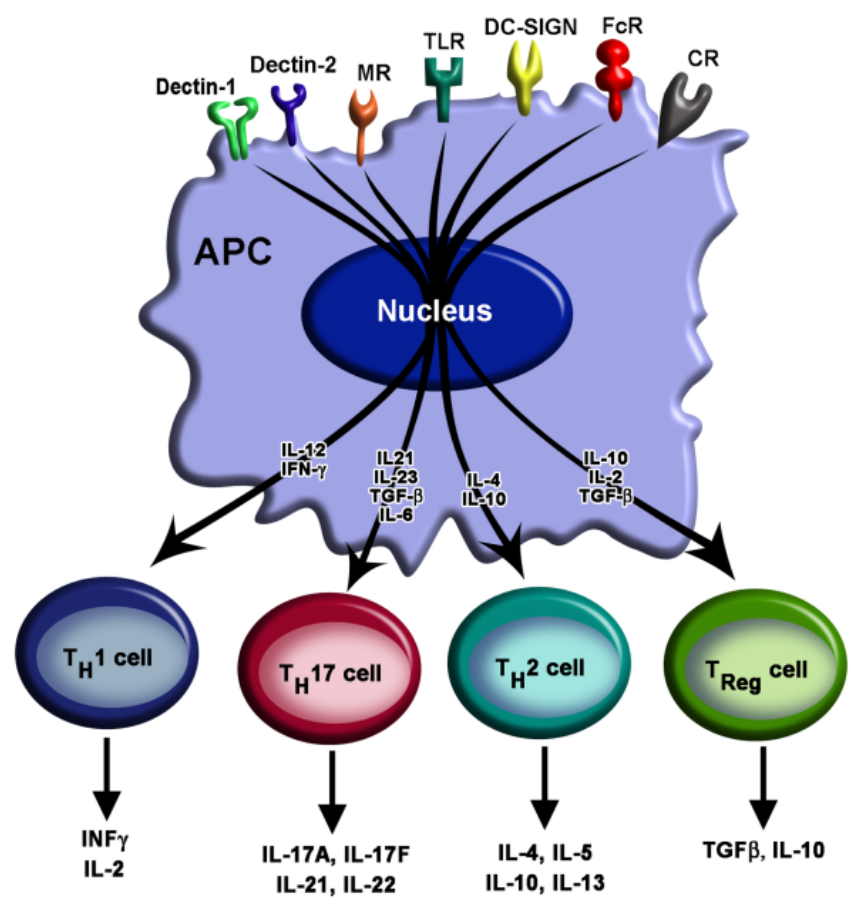

Figure 14. APC-derived cytokines and $\mathrm{T}_{\mathrm{H}}$ cell polarization. Pattern-Recognition Receptors (PRR): Dectin-1, Dectin-2, mannose receptor (MR), Toll-like receptor, DC-SIGN (Dendritic Cell-Specific Intercellular adhesion molecule-3-Grabbing Non-integrin), Fc receptor (FcR) - binding specificity for a Fc region of immunoglobulins, complement receptor (CR) - receptor of the complement system

It has been documented that the surface with neutral hydrophilic surface properties was found to show the greatest inhibition of cell adhesion and IL-1, IL- 6 and TNF- $\alpha$ release [72]. Recently, Brodbeck et al. have demonstrated that the surface chemistry (hydrophilicity and surface charge) of the biomaterial modulates the expression of anti- and pro-inflammatory $\mathrm{T}_{\mathrm{H} 1}$ and $\mathrm{T}_{\mathrm{H}} 2$ cytokines [71]. The influence of the PETOX100 and AEOX10 treatments of the mouse lymphoid line P388.D1 [clone 3124] on the changes of the IL-1 $\alpha$, IL-6 and TNF- $\alpha$ was evaluated. The exposition of P388.D1 macrophages with both AEOX10 and PETOX100 resulted in significant enhancement of IL-1 $\alpha$ IL-6 and TNF- $\alpha$ compared to the baseline 
results at immediately after the PETOX100 treatment. When compared to the time-kinetics of untreated cell control, the significance was confirmed only for TNF- $\alpha$ after 24 hours of exposure. The observed secretion levels of cytokines were significantly (10-100 times, depending on cytokine) lower than the cytokine levels observed with classical bacterial inducer, such as LPS. Based on these results, it could be assumed that both polymers, AEOX10 and PETOX100, represent bioavailable materials with immunobiological properties without strong undesirable inflammatory effectiveness with respect to their capacity to induce pro-inflammatory cytokines [70].

Apart from enzyme linked immunosorbent assay (ELISA) the more sensitive bead-based multiplex immunoassay for the flow cytometer and the enzyme linked immunosorbent spot assay (ELISpot) are frequently used for quantitative follow up of cytokine secretion by APC cells (Fig. 15).
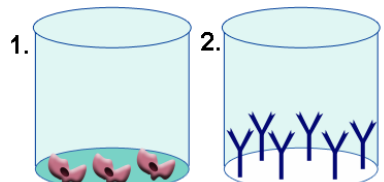

3.

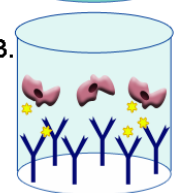

4.
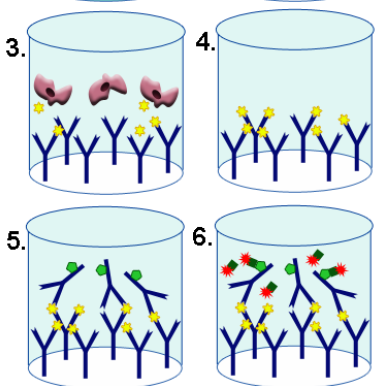

6.
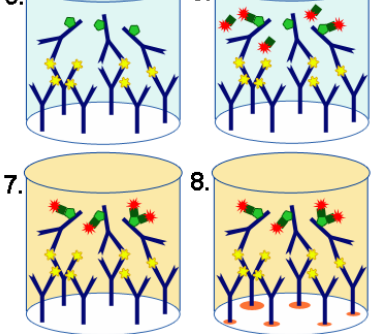

9.

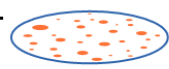

1. antigen activation of cells in cell - culture plate

2. 96 - membrane bottomed well plate is activated with ethanol and cytokine-specific antibodies are immobilized on membrane

3. pre - activated cells are transferred to coated wells and secreted cytokine is captured by primary antibody

4. removing of cells by washing, cytokines remine bound to the primary antibodies

5. detection antibody either directly conjugated with enzyme or biotinylated is added, detection antibody bounds to cytokine - antibody complex

6. if biotinylated detection antibody is used, a streptavidin-enzyme conjugate is added

7. incubation with detection substrate

8. substrate is converted into colored product and form a colored spot around the secreting cells

9. evaluation of resulting spots by spots counting in stimulated cultures and controls without stimulus, the frequency of responding cells could be determined

$$
\begin{aligned}
& \text { W - cytokine secteating cell } Y \text {-capture antibody } \\
& \text { - cytokine } Y \text { - biotinylated secondary antibody } \\
& \text { - streptavidin - enzyme conjugate - - spot }
\end{aligned}
$$

Figure 15. Scheme of ELISpot assay for quantification of cytokine one cell-based production.

Ultra-sensitive ELISPOT assays (limit of detection less than 1 in 100,000) can provide accurate measurements of antigen-specific cell immune responses and cytokine release. ELISPOT assays can measure both the magnitude and the quality of the response, thus providing more information about the samples in comparison with other methods for determination of cytokines e.g. ELISA. The methodology of ELISpot (developed by Czerkinsky et al. [73]) is rational up-grade of previously used plaque forming cells (PFC) technique with combination of enzyme immunoassay. ELISPOT assay was originally 
developed to enumerate B lymphocytes secreting antigen-specific antibodies. Nowadays, this technique has been adapted also for the identification and enumeration of cytokineproducing cells at the single cell level. ELISPOT assay allows visualization of the secretory product of individual activated or stimulated cells. Each spot represents an antigen-induced response of single reactive cell. Thus, the ELISPOT assay provides both qualitative (type of cytokine, antibody etc.) and quantitative (number of responding cells) information [74].

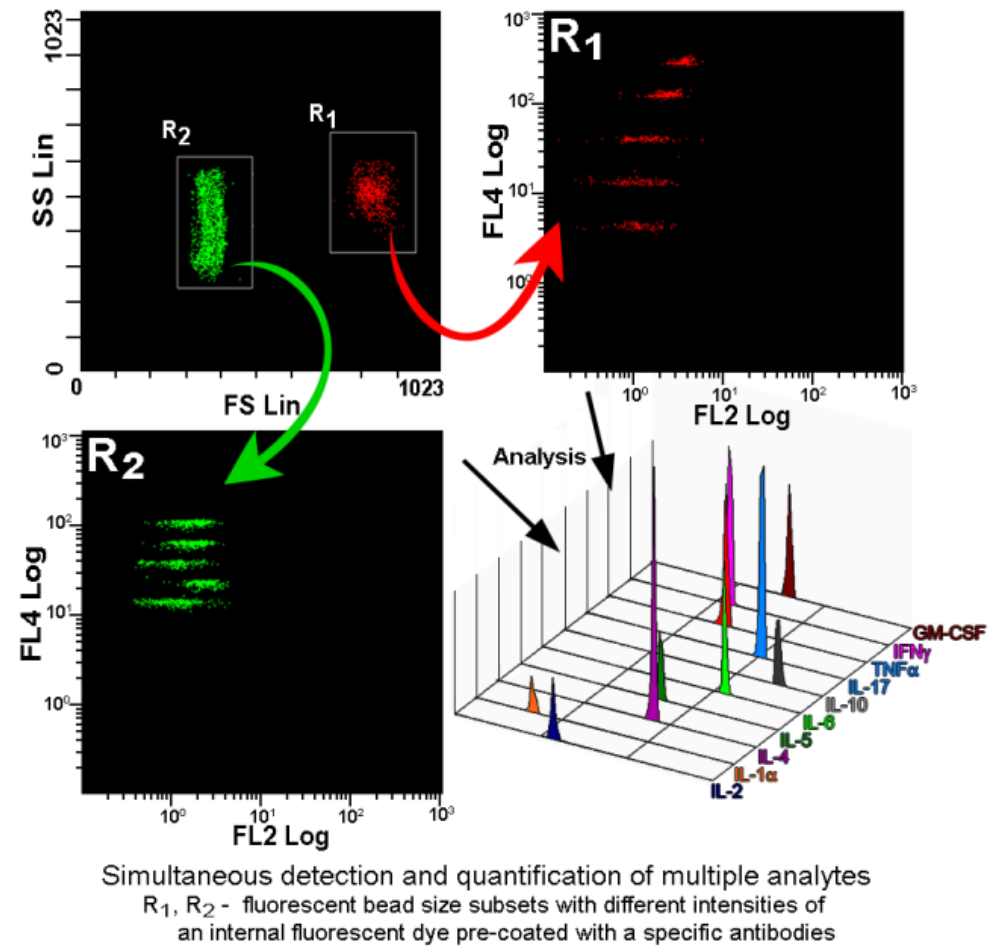

Figure 16. Example of FlowCytomix ${ }^{\mathrm{TM}}$ simultaneous quantification of Th1, Th2, Th17 and Treg cytokines in mice splenocytes (unpublished data)

Bead-based multiplex immunoassays for the immunocytometry are applied for the multiple detection of cytokines, chemokines, growth factors and related proteins. The FlowCytomix ${ }^{\mathrm{TM}}$ Multiple Analyte Detection System is designed to simultaneously quantify up to 20 protein targets. The methodology significantly reduces sample volumes and time compared to traditional ELISA and Western blot techniques. The FlowCytomix technology is based on the sandwich immunoassay technology where microspheres are used as a solid phase instead of a 96-well plate (Fig. 16). Within two bead size populations $4 \& 5 \mu \mathrm{m}$ latex beads coated with specific antibodies are multiple bead subsets, differentiated by varying intensities of an internal fluorescent dye Starfire Red. This dye can be excited at $488 \mathrm{~nm}$ by an Argon, He-Ne, or UV laser, and emits at $690 \mathrm{~nm}$ (the far red spectrum), which is detected in the FL-3/FL-4 channel. The combination of the two different bead sizes and different internal dye intensities 
makes it possible to distinguish up to 20 bead sets in one fluorescent channel. Reporter fluorochrome PE bound to strepavidin, binds to the biotin conjugate, emits at $578 \mathrm{~nm}$ and is detected in the FL-2 channel, allowing the quantification of the cytokine.

\section{In vitro and in vivo visualization methods}

The in vivo applications of polymers require investigating the intracellular metabolic pathways of distribution of polymer in cells and tissues. This can be examined by employing labeled systems. One way is the utilization of fluorescent probes for the visualization through labelling or staining. Labelled polymeric materials can be used for monitoring of cell uptake of desired materials using fluorescence microscopy or confocal laser scanning microscopy (CLSM). CLSM is a technique for obtaining high-resolution optical images with high depth resolution. This technique is widely used in cell biology, genetics, microbiology or developmental biology. Clinically, CLSM is an important method for the evaluation of different diseases, in endoscopic procedures and also in pharmaceutics for imaging the drug distribution. In the field of biocompatible polymers, this technique can be employed for the imaging of polymer uptake and distribution in cell, tissues or whole organs. For example, MCF-7 cancer cell uptake of coumarin-6-loaded poly(lactic-co-glycolic acid) (PLGA) nanoparticles was visualized using CLSM technique by overlaying the images obtained through the FITC filter and the PI filter [75]. The described system was used for sustainable release of Taxol in the treatment of cancer. CLSM was used for the examination of cell uptake and gene release from the ternary polyplexes of the plasmid DNA with B-PEI and $\mathrm{pH}$ responsive diblock copolymer poly(2-ethyl-2-oxazoline)-block-poly(methacrylic acid) (PETOX-b-PMAA) [76]. Time-dependent observations in three channels (green fluorescence of LysoTracker, blue fluorescence of 4',6-diamidino-2-phenylindole -DAPI andred channel of Cyanin 5.5) revealed the cell uptake process of the polyplex started after 3 hours and accelerated after 6 hours of incubation. Nanoparticles composed of statistical copolymers prepared by cationic copolymerization 2-ethyl-2-oxazoline and 2-decenyl-2oxazoline were prepared for encapsulation of various biomolecules [77]. Their cellular uptake of the prepared nanoparticles labeled with fluorescein was monitored with CLSM. Confocal micrographs revealed a high loading of mouse connective tissue fibroblasts with nanoparticles although no transfection agents were used to promote particle uptake. The overlay of the transmission and the fluorescence image shows the uniform distribution of the particles in intracellular compartments after endocytosis, which is the common way for the nanoparticle uptake. The results obtained by confocal microscopy were confirmed by flow cytometry. It was showed that the particles did not show toxic effects during the time of incubation.

Biodistribution of PETOX labeled with pyrene moiety in cells has been monitored by the Carl-Zeiss confocal laser-scanning microscopy [63]. The cuts of the treated cells were used for constructing 3D model (Fig. 17). The confocal micrographs supported the hypothesis of the polymer accumulation in specific organelles as observed also in the case of fluorescence microscopy measurements. 


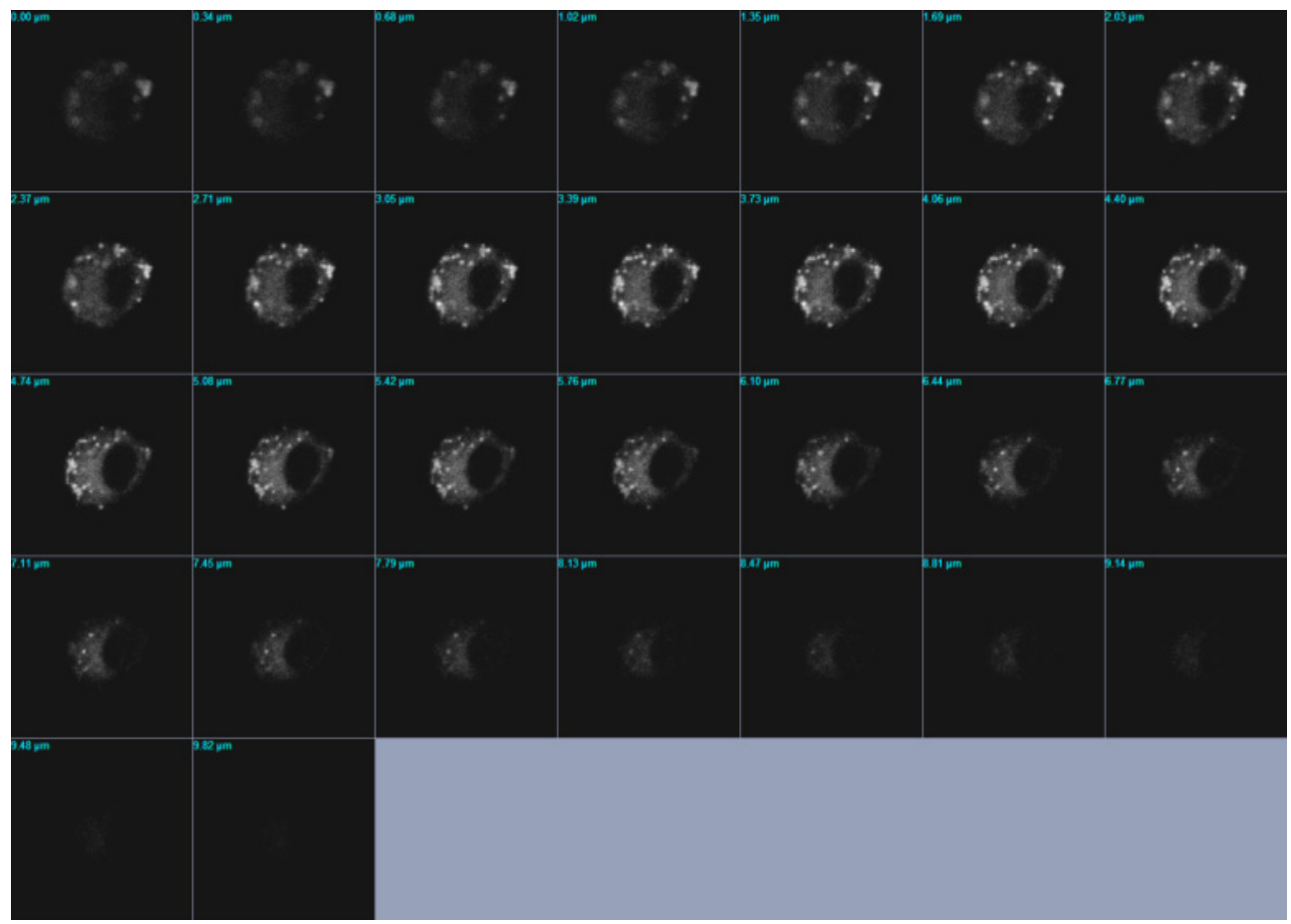

Figure 17. The cuts of the mouse macrophages treated loaded with pyrene-labeled PETOX conducted on the Carl-Zeiss confocal laser-scanning microscopy.

Similarly, cell uptake of polymers can be examined by fluorescence microscopy. A fluorescence microscope is an optical microscope used to study properties of organic or inorganic substances using the phenomena of fluorescence using two filters. An illumination (or excitation) filter ensures almost monochromatic excitation of a sample and a second emission (or detection) filter which ensures none of the excitation light source reaches the detector. The technique of fluorescence microscopy has become an essential tool in biology and the biomedical sciences, as well as in materials science due to attributes that are not readily available in other contrast modes with traditional optical microscopy. The application of an array of fluorochromes has made it possible to identify cells and submicroscopic cellular components with a high degree of specificity amid non-fluorescing material. In fact, the fluorescence microscope is capable of revealing the presence of a single molecule. Different probes can simultaneously identify several target molecules through the use of multiple fluorescence labeling. Although the fluorescence microscope cannot provide spatial resolution below the diffraction limit of specific specimen features, the detection of fluorescing molecules below such limits is readily achieved. Recently, infrared microscopy became very powerful method for optical visualization in the fields of biology, biochemistry, microbiology or genetics. Fluorescence microscopy was used for the visualization of cellular uptake of 2-oxazoline polymers. The principle was related to 
experiments on CLSM. Studied polymers were labeled with fluorescent probe. For these purposes, a pyrene moiety was introduced into the macromolecule of poly(2-ethyl-2oxazoline) (PETOX-py) using 1-(bromoacetyl)pyrene as initiator of cationic polymerization of 2-ethyl-2-oxazoline (Fig. 18).
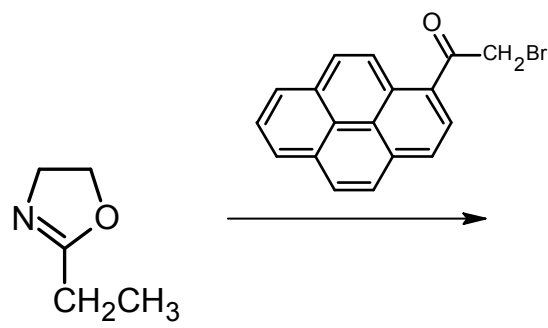

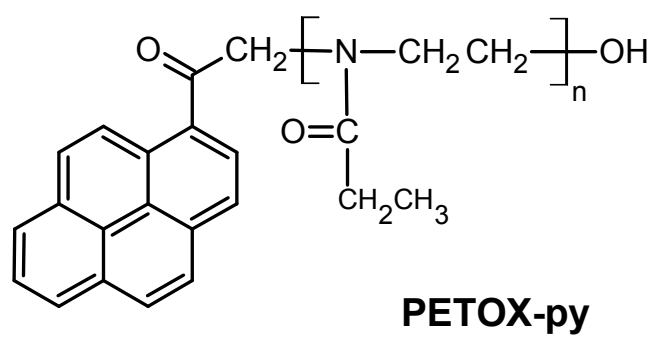

Figure 18. Synhesis of pyrene-labeled poly(2-ethyl-2-oxazoline) (PETOX-py).

Pyrene-based probes are in a class of hydrophobic dyes and can be used not only for the visualization and analysis of polymer concentrations within cells but also for the investigation of the environment polarity and the formation of agglomerates. Fig.19 shows the fluorescence microscopy of Rat-2 fibroblasts incubated in the presence of PETOX-py in PBS with the concentration of $5 \mathrm{mg} / \mathrm{ml}$. It can be seen that macromolecules are accumulated in the cells in specific organelles, most probably in peroxisomes [63].

(a)

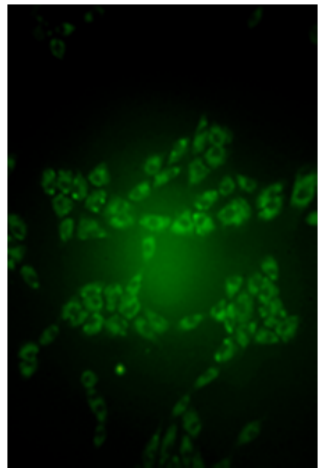

(b)

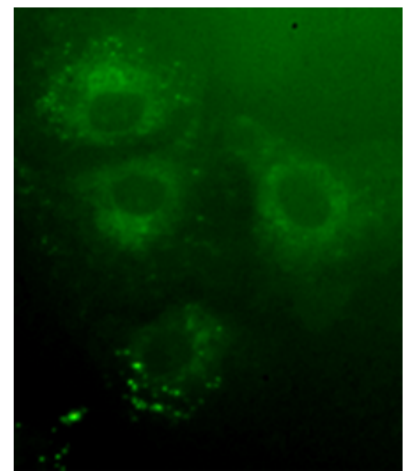

Figure 19. Fluorescence micrographs of rat fibroblasts loaded with pyrene-labeled PETOX for 24 hours in DMEM medium in the concentration equal to $5 \mathrm{~mol} / \mathrm{l}$ (a) and a detail of polymer uptake in cells (b). 
Peroxisomes are small membrane-enclosed organelles that contain enzymes involved in a variety of metabolic reactions, including several aspects of energy metabolism. Peroxisomes contain at least 50 different enzymes, which are involved in a variety of biochemical pathways in different types of cells. Peroxisomes were defined as organelles that carry out oxidation reactions leading to the production of hydrogen peroxide. A variety of substrates are broken down by such oxidative reactions in peroxisomes, including uric acid, amino acids, and fatty acids [78].

Biodistribution, targeting and excretion can also be investigated by radiolabeled poly(2alkyl-2-oxazolines). Authors used ${ }^{111}$ In-labeled polymers to study the distribution and excretion of such polymers in mice [79]. Similarly, ${ }^{125}$ I-labeled 2-oxazoline-based copolymers were examined after their intravenous administration to mice, and their biodistribution was assessed [80]. Beside the described visualization techniques, other modern methods such as scanning electron microscopy (SEM), transmission electron microscopy (TEM), atomic force microscopy (AFM) or tomography are available for the analysis of biodistribution.

\section{Conclusion}

The aim of this chapter was to survey the currently used experimental methods for evaluation of polymeric materials in biological systems concerning various methods for biocompatibility, immunological, bioimmunological and immunotoxicological assessment. This covers practical aspects throughout assay development and specific methodology adjustment. Decisive stages in development and application of these methods and practical suggestions are discussed. Such kind of research is essential due to enormous progress in the development of polymeric materials for different biomedical applications.

Among a number of polymers suitable for the use in medicine, poly(2-oxazolines) belong to polymeric materials with a great potential for different biomedical application. Their possible application areas in biological and medicinal contexts were reported. Especially the drug delivery, gene therapy and tissue engineering belong to the principal areas of their applications. Nowadays, several immunobiological and immunotoxicological methods were employed for the assessment of their biocompatibility and bioavailability. In vitro cytotoxicity of poly(2-oxazolines) was evaluated mainly by colorimetric MTT assay. However, other laboratory methods, like XTT, TB, SRB or WST assays, can be also used. All published results proved high biocompatibility of poly(2-oxazolines). Additionally, polymers prepared by cationic polymerization of 2-alkyl-2-oxazolines behave as "stealth" materials. This behaviour was confirmed by several independent immunological methods. Selected techniques as flow cytometric evaluation of phagocyte functions, immunocytometric determination of $\mathrm{T}_{\mathrm{H}} 1 / \mathrm{T}_{\mathrm{H}} 2 / \mathrm{T}_{\mathrm{H}} 17$ cytokines and ELISpot evaluation of cytokine producing cells comprise novel approaches to characterise immunomodulation of basic functions of immune competent cells targeted with poly(2-oxazolines). Last part of the chapter summarized in vitro and in vivo visualisation methods. 


\section{Author details}

Juraj Kronek, Zuzana Kroneková and Jozef Lustoň

Polymer Institute, Centre of Excellence GLYCOMED, Slovak Academy of Sciences, Bratislava, Slovakia

Ema Paulovičová and Lucia Paulovičová

Institute of Chemistry, Centre of Excellence GLYCOMED, Slovak Academy of Sciences, Bratislava, Slovakia

\section{Acknowledgement}

The authors appreciate the financial support of the Slovak Scientifical Agency VEGA in the Project nr. 2/0151/12 and the Centre of Excellence of the Slovak Academy of Sciences with the acronym GLYCOMED.

\section{References}

[1] He C, Kim SW, Lee DS (2008) In situ gelling stimuli-sensitive block copolymer hydrogels for drug delivery. J. control. release.127: 189-207.

[2] Roy I, Gupta MN (2003) Smart Polymeric Materials: Emerging Biochemical Applications. Chem. biol.10: 1161-1171.

[3] Jeong B, Gutowska A (2002) Lessons from nature: stimuli responsive polymers and their biomedical applications. TRENDS in biotechnol. 20: 305-311.

[4] Ř́hová B (2000). Immunocompatibility and biocompatibility of cell delivery systems. Adv. drug deliv. rev. 42: 65-80.

[5] Ř́hová B (1996) Biocompatibility of biomaterials: haemocompatibility, immunocompatibility and biocompatibility of solid polymeric materials and soluble targetable polymeric carriers. Adv. drug deliv. rev. 21: 157-176.

[6] Shalaby SW (1994) Biomedical Polymers: Designed-to-Degrade Systems. Cincinnati, USA: Hansen/Gardner Publ. ISBN 3-446-16531-2.

[7] Brauer H, Bienenstock J, Stead RH (2003) Mucosal Immunology. Munich: Sankyo Pharma GmbH. pp.1-63.

[8] Caminshi I, Shortman K (2012) Boosting antibody responses by targeting antigens to dendritic cells. Trends in immunol. 33: 71-77.

[9] McKenna AS, Beignon N, Bhardwaj A (2005): Plasmacytoid Dendritic Cells: Linking Innate and Adaptive Immunity. J. virol. 79: 17-27.

[10] Pulendran B, Palucka K, Banchereau J (2001) Sensing Pathogens and Tuning Immune Responses. Science. 293: 253-256.

[11] Kawai T, Akira S (2010) The role of pattern-recognition receptors in innate immunity: update on Toll-like receptors. Nat. immun. 11: 275-384.

[12] van Duin D, Medzhitov R, Shaw AC (2006) Triggering TLR signaling in vaccination. Trends in immunol. 27: 49-55. 
[13] Ishii KJ, Koyama S, Nakagawa A, Coban C, Akira S (2008) Host Innate Immune Receptors and Beyond: Making Sense of Microbial Infections, Cell host \& microbe, 2008: 352-363.

[14] Franz S, Rammelt S, Scharnweber D, Simon JC (2011) Immune responses to implants. A review of the implications for the design of immunomodulatory biomaterials. Biomaterials, 32: 6692-6709.

[15] Reddy ST, Swartz MA, Hubbell JA (2006) Targeting dendritic cells with biomaterials: developing the next generation of vaccines. Trends in immunol. 27: 573-579.

[16] Demento SL, Siefert AL, Bandyopadhyay A, Sharp FA, Fahmy TM (2011) Pathogenassociated molecular patterns on biomaterials: a paradigm for engineering new vaccines. Trends in biotechnol. 29: 294-306.

[17] Anderson JM, Cook G, Costerton B, Hanson SR, Hensten- Pettersen A. Jacobsen N, Johnson RJ, Mitchell RN, Pasmore M, Schoen FJ, Shirtliff M, Stoodley P (2004) Host Reactions to Biomaterials and Their Evaluation. In: Biomaterials Science, Elsevier Inc.2nd Edition, chapter 4: 293-338.

[18] Říhová B (2002) Immunomodulating activities of soluble synthetic polymer-bound drugs. Adv. drug deliv. Rev. 54: 653-674.

[19] Nilsson B, Korsgren O, Lambris JD, Nilsson Ekdahl K (2009) Can cells and biomaterials in therapeutic medicine be shielded from innate immune recognition? Trends in immunol. 31: 32-38.

[20] Kobayashi S (1990) Ethylenimine polymers. Prog. polym. sci. 15: 751-823.

[21] Weberskich R, Hettich R, Nuyken O, Schmaljohann D, Voit B (1999) Synthesis of new amphiphilic star polymers derived from a hyperbranched macroinitiator by the cationic 'grafting from' method. Macrom. Chem. Phys. 200: 863-73.

[22] Kowalczuk A, Kronek J, Bosowska K, Trzebicka B, Dworak A (2011) Star poly(2-ethyl-2oxazoline)s - synthesis and thermosensitivity. Polym. Int. 60: 1001-1009.

[23] Puts RD, Sogah DY (1997) Universal multifunctional initiator containing orthogonal reactive sites. Synthesis of macromonomers and comb polymers using consecutive controlled free radical and cationic ring-opening polymerizations. Macromolecules, 30: 7050-7055.

[24] Cesana S, Auernheimer J, Jordan R, Kessler H, Nuyken O (2006) First Poly(2-oxazoline)s with Pendant Amino Groups. Macrom. chem. phys. 207: 183-192.

[25] Cesana S, Kurek A, Baur MA, Auernheimer J, Nuyken O (2007) Polymer-Bound Thiol Groups on Poly(2-oxazoline)s. Macromol. rapid commun. 28: 608-615.

[26] Taubmann C, Luxenhofer R, Cesana S and Jordan R (2005) First AldehydeFunctionalized Poly(2-oxazoline)s for Chemiselective ligation. Macromol. Biosci. 5: 603612.

[27] Kronek J, Lustoň J, Kroneková Z, Paulovičová E, Farkaš P, Petrenčíková N, Paulovičová L, Janigová I (2010) Synthesis and bioimmunological efficiency of poly(2-oxazolines) containing a free amino group. J. mater. sci. mater. med. 21: 879-886.

[28] Christova D, Velichkova R. Loos W, Goethals EJ, Du Pre, F (2003) New thermoresponsive polymer materials based on poly(2-ethyl-2-oxazoline) segments. Polymer, 44: 2255-2261. 
[29] Park JS, Akiyama Y, Winnik FM, Kataoka K (2004) Versatile synthesis of endfunctionalized thermosensitive poly(2-isopropyl-2-oxazolines). Macromoleules, 37: 6786-6792.

[30] Bloksma MM, Paulus RM, van Kuringen HPC, van der Wert F, Lamberhort-Thijs HML, Schubert US, Hoogenboom R (2012) Thermoresponsive Poly(2-oxazine)s. Macrom. rapid commun. 33: 92-96.

[31] Charrois GJR, Allen TM (2004) Drug release rate influences the pharmacokinetics, biodistribution, therapeutic activity, and toxicity of pegylated liposomal doxorubicin formulations in murine breast cancer, Biochim. Biophys. acta, 1663: 167-177.

[32] Zalipsky S, Hansen CB, Oak JM, Allen TM (1996) Evaluation of blood clearance rates and biodistribution of poly(2-oxazoline)-grafted liposomes. J. pharm. sci. 85: 133.

[33] Luedtke K, Jordan R, Hommes P, Nuyken O, Naumann CA (2005) Lipopolymers from new 2-substituted-2-oxazolines for artificial cellmembrane constructs, Macromol. biosci. 5: 384-393.

[34] Lee SC, Kim C, Kwon IC, Chung H, Jeong SY (2003) Polymeric micelles of poly(2-ethyl2-oxazoline)-block-poly(caprolactone) copolymer as a carrier for paclitaxel. J. control. rel. 89: 437-446.

[35] Wang CH, Hwang YS, Chiang PR, Shen CR, Hong WH, Hsiue GH (2012) Extended Release of Bevacizumab by Thermosensitive Biodegradable and Biocompatible Hydrogel. Biomacromolecules, 13: 40-48.

[36] Zschoche S, Rueda JC, Binner M, Komber H, Janke A, Arndt KF, Lehmann S, Voit B (2012) Reversibly Switchable pH/ and Thermoresponsive Core-Shell Nanogels Based on Poly(NiPAAm)-graft-poly(2-carboxyethyl-2-oxazoline)s. Macromol. chem. phys. 213: 215-226.

[37] Donev R, Koseva N, Petrov P, Kowalczuk, Thome J (2011) Characterization of different nanoparticles with potential use for drug delivery in neuropsychiatric disorders. World j. biol. psych. 12: 44-51.

[38] Thomas M, Lu JJ, Ge Q, Zhang CC, Cheng JZ, Klibanov AM (2005) Full deacylation of polyethylenimine dramatically boots its gene delivery efficiency and specifity to mouse lung. Proc. nat. acad. sci. USA, 102: 5679-5684.

[39] Hsiue GH, Chiang HZ, Wang CH, Juang TM (2006a) Nonviral gene carriers based on diblock copolymers of poly(2-ethyl-2-oxazoline) and linear polyethylenimine. Bioconjug. chem. 17: 781-786.

[40] Tauhardt L, Kempe K, Knop K, Altuntas E, Jager M, Schubert S, Fischer D, Schubert US (2011) Linear Polyethyleneimine: Optimized Synthesis and Characterization - On the Way to "Pharmagrade" Batches. Macromol. chem. phys. 212: 1918-1924.

[41] Banerjee P, Weissleder R, Bogdanov A (2006) Linear polyethyleneimine- grafted to hyperbranched poly(ethylene glycol)-like core: a co-polymer for gene delivery. Bioconjug. chem. 17: 125-131.

[42] Halacheva S, Price GJ, Garamus VM (2011) Effect of Temperature and Polymer Composition upon the Aqueous Solution Properties of Comblike Linear Poly(ethylene imine)/Poly(2-ethyl-2-oxazoline)-Based Polymers. Macromolecules, 44: 7394-7404. 
[43] Von Erlach T, Zwicker S, Pidhatika B, Konradi R, Textor M, Hall H, Luhmann T (2011) Formation and characterization of DNA-polymer-condensates based on poly(2-methyl2-oxazoline) grafted poly(L-lysine) for non-viral delivery of therapeutic DNA. Biomaterials, 32: 5291-5303.

[44] Brissault B, Kichler A, Leborgne C, Jarroux N, Cheradame H, Guis C (2007) Amphiphilic poly[(propylene glycol)-block-(2-methyl-2-oxazoine)] copolymers for gene transfer in skeletal muscle. ChemMedChem 2: 1202-1207.

[45] Farkas P, Korcova J, Kronek J, Bystricky S (2010) Preparation of synthetic polyoxazoline based carrier and Vibrio cholerae O-specific polysaccharide conjugate vaccine. Eur. j. med. chem. 45: 795-799.

[46] Korcova J, Machova E, Farkas P, Bystricky S (2010) Immunomodulative properties of conjugates composed of detoxified lipopolysaccharide and capsular polysaccharide of Vibrio cholerae O135 bound to BSA-protein carrier. Biologia, 65: 768-775.

[47] Waschinski CJ, Tiller JC (2005) Poly(oxazoline)s with telechelic antimicrobial functions, Biomacromolecules, 6: 235-243.

[48] Schmidt DL, Brady RF, Lam K, Schmidt DC \& Chaudhury MK (2004) Contact angle hysteresis, adhesion and marine biofouling. Acta biomater. 20: 2830-2836.

[49] Choi JW, Lim IH, Kim HH, Min JH, Lee WH (2001) Optical perxide biosensor using the electrically controlled-release technique. Biosensors\&Bioelectronic, 16: 141-146.

[50] Purrucker O, Goennenwein S, Foertig A, Jordan R, Rusp M, Baermann M, Moroder L, Sackmann E, Tanaka M (2007) Polymer-tethered membranes as quantitative models for the study of integrin-mediated cell adhesion. Soft matter, 3:333-336.

[51] Luedtke K, Jordan R, Furr N, Garg S, Forsythe K, Naumann CA (2008) Twodimensional center-of-mass diffution of lipid-tethered poly(2-methyl-2-oxazoline) at the air-water interface studied at the single molecule. Langmuir, 24: 5580-5584.

[52] Reif M, Jordan R (2011) Alpha,omega-Functionalized Poly(2-Oxazoline)s Bearing Hydroxyl and Amino Functions. Macrom. chem. phys. 212: 1815-1824.

[53] Dech S, Wruk V, Fik CP, Tiller JC (2012) Amphiphilic polymer conetworks derived from aqueous solutions for biocatalysis in organic solvents. Polymer, 53: 701-707.

[54] Adeli M, Zarnegar Z, Kabiri R (2008) Amphiphilic star copolymers containing cyclodextrin core and their application as nanocarrier. Eur. polym. j. 44: 1921-1930.

[55] Williams DF (1999) In William's dictionary of Biomaterials. Liverpool University Press. ISBN 0-85323-921-5.

[56] Mosmann T (1983) Rapid Colorimetric Assay for Cellular Growth and Survival: Application to Proliferation and Cytotoxicity Assays, J. immunol. methods, 65: 55-63.

[57] Ishiyama M, Shiga M, Sasamoto K, Mizoguchi M, He PG (1993) A new sulfonated tetrazolium salt that produces a highly water-soluble formazan dye, Chem. pharm. bull. 41: 1118-1122.

[58] Coppeta R (1998) Dual Emission Laser Induced Fluorescence for Direct Planar Scalar Behavior Measurements. Experiments in Fluids, 1998: 1-15.

[59] Hoffman RM (1991) In vitro sensitivity assays in cancer: a review, analysis, and prognosis. J. clin. lab. anal. 5: 133-143. 
[60] Jeong JH, Song SH, Lim DW, Lee H, Park TG (2001) DNA transfection using linear poly(ethylenimine) prepared by controlled acid hydrolysis of poly(2-ethyl-2-oxazoline). J. control. rel. 73: 391-399.

[61] Hsiue GH, Wang CH, Lo CL, Wang CH, Li JP, Yang JL (2006) Environmental-sensitive micelles based on poly(2-ethyl-2-oxazoline)-b-poly(L-lactide) diblock copolymer for application in drug delivery. Int. j. pharm. 317: 69-75.

[62] Luxenhofer R, Sahay G, Schulz A, Alakhova D, Bronich TK, Jordan R, Kabanov AV Structure-property relationship in cytotoxicity and cell uptake of poly(2-oxazoline) amphiphiles. J. control. rel. 153: 73-82.

[63] Kronek J, Kroneková Z, Lustoň J, Paulovičová E, Paulovičová L, Mendrek B (2011) In vitro bio-immunological and cytotoxicity studies of poly(2-oxazolines). J. mater. sci. mater. med. 22: 1725-1734.

[64] Ross D (1996) Metabolic basis of benzene toxicity. Eur. j. hemat. 57: 111-118.

[65] Klopman G, Shi LM, Ramu A (1997) Quantitative Structure-Activity Relationship of Multidrug Resistance Reversal Agents. Mol. pharm. 52: 323-334.

[66] Babior BM (2000) Phagocytes and oxidative stress. Am. j. med. 109: 33-44.

[67] Gomes A, Fernandes E, Lima JLFC (2005) Fluorescence probes used for detection of reactive oxygen species. J. biochem. biophys. Methods, 65: 45-80.

[68] Brown M, Wittwer C (2000) Flow cytometry: Principles and Clinical Applications in Hematology. Clinical chem. 46: 1221-1229.

[69] Shapiro HM (2003) In: Practical Flow cytometry. J.Wiley \& Sons, Inc. 4th. Edition: 1-562.

[70] Kronek J, Paulovičová E, Paulovičová L, Kroneková Z, Lustoň J (2012). Immunomodulatory efficiency of poly(2-oxazolines). J. mater. sci. mater. med. 23: 14571464.

[71] Brodbeck WG, Nakayama Y, Matsuda T, Colton E, Ziats NP, Anderson JM (2002). Biomaterial surface chemistry dictates adherent monocyte/macrophage cytokine expression in vitro. Cytokine, 18: 311-319.

[72] Bernatchez SF, Merkli A, Minh TL, Tabatabay C, Anderson JM, Gurny R (1994). Biocompatibility of a new semisolid bioerodible poly(orthoester) intended for ocular delivery of 5-fluorouracil. J. biomed. mater. res. 28: 1037-1046.

[73] Czerkinsky C, Nilsson L, Nygren H, Ouchterlony O, Tarkowski A (1983). A solid-phase enzyme-linked immunospot (ELISPOT) assay for enumeration of specific antibodysecreting cells. J. immunol. methods, 65: 109-121.

[74] Kalyuzhny AE (2005). Handbook of ELISPOT. In Methods in Molecular Biology, Vol. 302, pp.1-323, Humana Press Inc.

[75] Feng SS, Zhao L, Zhang Z, Bhakta G, Win KY, Dong Y, Chien S (2007). Chemotherapeutic engineering: Vitamin E TPGS-emulsified nanoparticles of biodegradable polymers realized sustainable paclitaxel chemotherapy for $168 \mathrm{~h}$ in vivo. Chem. eng. sci. 62: 6641-6648.

[76] Lin CP, Sung YC, Hsiue GH (2011). A pH Responsive Ternary Gene Carrier based on Branched-Poly(ethylenimine) and Poly(2-ethyl-2-oxazoline)-block-Poly(methacrylic acid). Biotech. biomater. 1: 1-8. 
[77] Kempe K, Vollrath A, Schaefer HW, Poehlmann TG, Biskup C, Hoogenboom R, Hornig S, Schubert US (2010). Multifunctional Poly(2-Oxazoline) Nanoparticles for Biological Applications. Macrom. rapid commun. 31: 1869-1873.

[78] Cooper GM (2000) In: The cell: Molecular Approach. 2nd edition, Sunderland (MA): Sinauer Associates. ISBN-10: 0-87893-106-6.

[79] Gaentner FC, Luxenhofer R, Blechert B, Jordan R, Essler M (2007). Synthesis, biodistribution and excretion of radiolabeled poly(2-alkyl-2-oxazoline)s. J. control. rel. 119: 291-300.

[80] Goddard P, Hutchinson LE, Brown J, Brookman LJ (1989). Soluble polymeric carriers for drug delivery. Part 2. Preparation and in vivo behavior of N-acylethyleneimine copolymer. J. control. rel. 10: 5-16. 